\title{
Genetic diversity in three natural populations of Pitcairnia flammea (I.) John (Bromeliaceae) estimated by ISSR markers
} and A.B.P.L. Gontijo 5

${ }^{1}$ Laboratório de Bioquímica e Biologia Molecular,

Programa de Pós-Graduação em Genética e Melhoramento,

Centro de Ciências Agrárias, Universidade Federal do Espírito Santo,

Alegre, ES, Brasil

2Departamento de Biologia, Centro de Ciências Agrárias,

Universidade Federal do Espírito Santo, Alegre, ES, Brasil

${ }^{3}$ Laboratório de Bioquímica e Biologia Molecular,

Programa de Pós-Graduação em Produção Vegetal, Centro de Ciências Agrárias,

Universidade Federal do Espírito Santo, Alegre, ES, Brasil

${ }^{4}$ Laboratório de Bioquímica e Biologia Molecular,

Departamento de Farmácia e Nutrição, Centro de Ciências Agrárias,

Universidade Federal do Espírito Santo, Alegre, ES, Brasil

${ }^{5}$ Departamento de Ciências Agrárias e Biológicas,

Centro Universitário Norte do Espírito Santo,

Universidade Federal do Espírito Santo, São Mateus, ES, Brasil

Corresponding author: T.C.B. Soares

E-mail: tcbsoares@yahoo.com.br

Genet. Mol. Res. 14 (4): 15892-15901 (2015)

Received June 23, 2015

Accepted September 18, 2015

Published December 3, 2015

DOI http://dx.doi.org/10.4238/2015.December.3.1

ABSTRACT. Bromeliads are greatly represented in the Atlantic Forest, although many species are threatened with extinction owing to habitat fragmentation and intense extraction for ornamental purposes. Therefore, it is necessary to conduct studies generating knowledge about genetic 
diversity and the distribution of this diversity among and within natural populations to establish conservation strategies. These studies can be performed with the use of molecular markers. Molecular markers are advantageous for studies of natural populations, for conservation programs, and to aid in properly classifying plant species. This study aimed to evaluate the genetic diversity among and within natural populations of Pitcairnia flammea, occurring in three fragments of the Atlantic Forest in the southern State of Espírito Santo through the use of inter-simple sequence repeat (ISSR) markers. DNA samples from 55 individuals were amplified with 18 ISSR primers, generating 180 bands, 159 of which were polymorphic. The Shannon genetic diversity index ranged from 0.348 to 0.465 , with an average of 0.412 . The Bayesian approach for the molecular data indicated the existence of two genetic groups. Analysis of molecular variance indicated the existence of $90.3 \%$ diversity within the population and $9.74 \%$ among populations. The amount of genetic differentiation of populations was moderate (0.0974), indicating that gene flow rates may be enough to counteract the effects of genetic drift. Greater genetic variability found in population B indicates that this area is an important source of genetic variability.

Key words: Bromeliads; Atlantic Forest; Inter-simple sequence repeat; Natural populations; Genetic diversity

\section{INTRODUCTION}

Over the last decade, the use of native Brazilian plants for landscaping and the accelerated devastation of some ecosystems have led to the irreparable loss of a large number of species, including some from the family Bromeliaceae. The family, which contains a rich diversity, including epiphytic, rupicolous, and terrestrial life forms, and a wide adaptive radiation in distinct habitats (Givnish et al., 2011), is considered one of the botanical families with greater morphological diversity, ecological plasticity, and species-rich clades of flowering plants native to the tropical and subtropical regions of the New World (Givnish et al., 2014). Pitcairnia is one genus of 44 in Brazil (Forzza et al., 2014), within the subfamily Pitcairnioideae (Givnish et al., 2011). Pitcairnia flammea is one of the most morphologically variable Pitcairnia species in Brazil and is widespread throughout the Atlantic Forest.

The Atlantic Forest is the most important tropical forest in the world and is considered a priority for conservation due to high fragmentation applied in the area, putting its megadiversity at risk (Martinelli et al., 2008). The effects of forest fragmentation are devastating and understanding these effects is essential to biodiversity conservation. It can reduce and isolate populations, favoring endogamy and genetic drift, reducing the genetic variation, and leading to a risk of extinction (reviewed by Pamponét et al., 2013). Therefore, gaining knowledge of the genetic diversity represents a key step for conservation programs, indicating areas and populations with a different level of importance for conservation (Cavallari et al., 2006).

The use of molecular markers, together with the description of the vegetative and reproductive traits of a species, is advantageous, for studies of natural populations for conservation 
programs, and to aid in appropriate classification of plant species. There are some studies on bromeliads in the genera: Aechmea, Tillandsia, Vriesea (Vieira et al., 2013), Alcantarea (Barbará et al., 2008), Bromelia (Zanella et al., 2012), Dyckia (Hmeljevski et al., 2011), Encholirium (Cavallari et al., 2006), Pitcairnia (Domingues et al., 2011), Puya (Sgorbati et al., 2004) and Neoglaziovia (Silveira et al., 2009). Studies reporting the genetic diversity and population structure for Pitcairnia flammea are not yet available in literature. ISSR (Inter-simple Sequence Repeats) markers are an appropriate tool for genetic characterization by speed and reproducibility, and for detection of high numbers of polymorphisms that are widely distributed in the genome (Verma et al., 2009).

This study aimed to evaluate the genetic diversity among and within natural populations of $P$. flammea, occurring in three fragments of the Atlantic Forest in the southern State of Espírito Santo by using ISSR markers.

\section{MATERIAL AND METHODS}

\section{Population sampling and DNA extraction}

Leaves of $P$. flammea were collected from three natural populations in the south of the Espírito Santo region (Table 1), 55 individuals in total. Populations were collected in the ecological corridor Burarama-Pacotuba-Cafundó, thus connecting fragments from the Atlantic forest of the Private Reserve of Natural Heritage Cafundo farm to the National Forest of Pacotuba in the South of Espírito Santo. Samples were collected linearly respecting the minimum distance of five meters between each individual. Leaf samples were stored in ice for DNA extraction. Genomic DNA was isolated according to the protocol described by Doyle and Doyle (1990). Sample concentrations were determined on $0.8 \%$ agarose gel stained with ethidium bromide, and using different tracer concentrations $(25,50$ and $75 \mathrm{ng} / \mu \mathrm{L})$.

Table 1. Details of populations studied.

\begin{tabular}{lccccc}
\hline Populations & Code & D & N & Latitude (S) & Longitude (W) \\
\hline Burarama 1 & A & $4.7($ A-B & 20 & $20^{\circ} 40^{\prime} 43.10^{\prime \prime}$ & $41^{\circ} 20^{\prime} 40.59^{\prime \prime}$ \\
Burarama 2 & B & $11.8($ A-C) & 24 & $20^{\circ} 41^{\prime} 47.89^{\prime \prime}$ & $41^{\circ} 23^{\prime} 05.66^{\prime \prime}$ \\
Alegre & C & $7.4(B-C)$ & 11 & $20^{\circ} 44^{\prime} 41.75^{\prime \prime}$ & $41^{\circ} 25^{\prime} 57.94^{\prime \prime}$ \\
Total & & 55 & &
\end{tabular}

$\mathrm{D}=$ distance between populations in kilometers; $N$ = number of individuals.

\section{PCR amplification}

Eighteen ISSR primers from the University of British Columbia, Vancouver, Canada, were used for genetic characterization of 55 individuals of $P$. flammea. Amplification reactions were performed in a total volume of $20 \mu \mathrm{L}$ containing $2.5 \mathrm{mM} \mathrm{MgCl}_{2}, 10 \mathrm{mM} / 50 \mathrm{mM}$ Tris/KCl, $\mathrm{pH}$ 8.3, $0.1 \mathrm{mM}$ each dNTP, $0.4 \mu \mathrm{M}$ primer, 1 unit Taq polymerase, and $30 \mathrm{ng}$ DNA. The following amplification conditions were used: initial denaturation at $94^{\circ} \mathrm{C}$ for $4 \mathrm{~min}$, followed by 35 cycles under the following conditions: initial denaturation $\left(94^{\circ} \mathrm{C}\right.$ for $\left.1 \mathrm{~min}\right)$, primer annealing $\left(52^{\circ} \mathrm{C}\right.$ for 1 $\min$ ) and extension $\left(72^{\circ} \mathrm{C}\right.$ for $\left.1 \mathrm{~min}\right)$. The final step is extension at $72^{\circ} \mathrm{C}$ for $7 \mathrm{~min}$. Amplification products were separated by electrophoresis on $2.5 \%$ agarose gels at $100 \mathrm{~V}$ for $4 \mathrm{~h}$ and stained with ethidium bromide. The gels were visualized by illumination with ultraviolet light and photographed 
for analysis. Molecular weight of the fragments was estimated using a GeneRuler 100bp DNA Ladder Plus (Fermentas Life Sciences).

\section{Statistical analysis}

The ISSR marker fragments visualized in the gels were computed as presence (1) or absence (0). The results of these data generated a binary matrix. We used the dissimilarity index of the arithmetic complement of the Jaccard coefficient (Jaccard, 1901) to estimate the distances between the pairs of individuals and obtained the similarity matrix. Individuals were grouped by hierarchical method UPGMA (unweighted pair group method with arithmetic averages). The cutoff point $(\mathrm{Pc})$ of the dendrogram was defined as proposed by Mojema (1977), followed by $\mathrm{Pc}=\mathrm{m}+$ $\mathrm{kdp}$ formula, with $\mathrm{m}$ being the average of the distance values of the levels corresponding to the melting stage; $k=1.25$ (Milligan and Cooper, 1985); SD = standard deviation. For the analysis of molecular variance (AMOVA) (Excoffier et al., 1992), individuals were grouped into populations, depending on where they were collected. All these analyses were performed using the program GENES (Cruz, 2013). The Shannon diversity index, another way to analyze the molecular genetic diversity (Shannon and Weaver, 1949) was estimated using the PopGene program version 1.32 (Yeh and Boyle, 1997). Bayesian clustering was performed using the STRUCTURE software (Pritchard et al., 2000). The program was run for 10,000 iterations, after a burn-in length of 10,000 iterations, to test population subdivision from $\mathrm{k}=1$ to $\mathrm{k}=5$, and thereby to check for any possible subdivision. Twenty runs were carried out for each $k$ value. The number of genetic groups was estimated by the DK value (Evanno et al., 2005) using the STRUCTURE HARVESTER software (Earl and vonHoldt, 2012).

\section{RESULTS AND DISCUSSION}

The set of 18 ISSR primers generated 180 fragments in the 55 individuals from three populations. Of these, 159 were polymorphic (approximately $88 \%$ polymorphism). The primer UBC843 amplified highest number of bands (19 bands), while the lowest number of bands occurred in the primer UBC813 ( 2 bands) with an average ten loci amplified by primer. Among the 18 selected primers, six (UBC813, UBC827, UBC834, UBC854, UBC859 and UBC864) showed $100 \%$ of polymorphic bands (Table 2). Great intraspecific genetic variability can be seen in $P$. flammea due to the high percentage of polymorphic bands (PBP). In bromeliads, a similar result was reported by Ribeiro et al. (2013), who studied the genetic diversity in Vriesea cacuminis with 16 ISSR primers and observed $87 \%$ polymorphism. However for the same gender studied in this work, Domingues et al. (2011) identified low polymorphism (35\%) with molecular markers of endangered natural populations.

The Shannon and Weaver (1949) index ranged from 0.348 to 0.465 , with an average of 0.412 (Table 3). The Shannon index ranges from 0 to 1 and considers that the closer a value is to zero, the lower the diversity will be. The average dissimilarity values of the arithmetic complement of the Jaccard coefficient per population, ranged from 0.385 to 0.543 . As has been observed for other species, including the Bromeliaceae family, the level of diversity varies according to the size of the population (Hmeljevski et al., 2011). The largest population examined, population B with 24 individuals, showed the highest Shannon index and average genetic dissimilarity. On the other hand, the smallest population, population C with 11 individuals, showed the lowest Shannon index values and average of genetic dissimilarity (Table 3 ). 
Table 2. ISSR primers used for Pitcairnia flammea with descriptions of sequence and the amplified results as the number of total bands (TB), polymorphic bands (PB) and \% of polymorphic bands (PPB).

\begin{tabular}{|c|c|c|c|c|}
\hline Primer & Sequence $\left(5^{\prime}-3^{\prime}\right)$ & TB & PB & PPB (\%) \\
\hline UBC 808 & AGAGAGAGAGAGAGAGC & 8 & 6 & 75.0 \\
\hline UBC 810 & GAGAGAGAGAGAGAGAT & 11 & 10 & 90.9 \\
\hline UBC 813 & стстстстстстTт & 2 & 2 & 100.0 \\
\hline UBC 819 & GTGTGTGTGTGTTA & 4 & 2 & 50.0 \\
\hline UBC 827 & ACACACACACACCG & 9 & 9 & 100.0 \\
\hline UBC 834 & AGAGAGAGAGAGAGAGYT & 10 & 10 & 100.0 \\
\hline UBC 841 & GAGAGAGAGAGAGAGAYC & 16 & 14 & 87.50 \\
\hline UBC 842 & GAGAGAGAGAGAAYG & 14 & 12 & 85.70 \\
\hline UBC 843 & СTCTCTCTCTCTCTCTRA & 18 & 17 & 94.50 \\
\hline UBC 849 & GTGTGTGTGTGTGTGTYA & 12 & 11 & 91.70 \\
\hline UBC 854 & TCTCTCTCTCTCTCTCRG & 7 & 7 & 100.0 \\
\hline UBC 859 & TGT GTGTGTGTGTGTGRC & 13 & 13 & 100.0 \\
\hline UBC 862 & AGCAGCAGCAGCAGCAGC & 6 & 3 & 50.0 \\
\hline UBC 864 & ATGATGATGATGATGATG & 11 & 11 & 100.0 \\
\hline UBC 880 & GGAGAGGAGAGGAGA & 12 & 11 & 91.7 \\
\hline UBC 881 & GGGTGGGGTGGGGTG & 11 & 8 & 72.7 \\
\hline UBC 889 & DBDACACACACACACAC & 9 & 7 & 77.8 \\
\hline UBC 890 & VHVGTGTGTGTGTGTGT & 7 & 6 & 85.7 \\
\hline Total & & 180 & 159 & \\
\hline
\end{tabular}

$\mathrm{Y}=\mathrm{C} / \mathrm{T}, \mathrm{R}=\mathrm{A} / \mathrm{G}$ UBC: ISSR primers, designed from University of British Columbia, Vancouver, Canada. SPI ISSR primer index.

Table 3. Genetic variation of Pitcairnia flammea populations.

\begin{tabular}{lccc}
\hline Population & Shannon index & Dissimilarity average & \% Polymorphism \\
\hline A & 0.348 & 0.385 & 63.888 \\
B & 0.465 & 0.543 & 82.222 \\
C & 0.425 & 0.498 & 68.333 \\
Species & 0.412 & 0.475 & 88.00 \\
\hline
\end{tabular}

The dissimilarity matrix obtained from 55 individuals resulted in 3025 dissimilarity index values, with an average of 0.47 , of which only 20 values of higher and lower dissimilarity stood out (Table 4). The pairs formed by individuals $7 \times 9$ and $42 \times 50$ established the shortest (0.125) and longest (0.838) distances respectively, being that, the ones with the shortest distance belong to the same population and the ones with the longest distance belong to different populations (B and $\mathrm{C}$ ). In Zhang et al. (2012), with 12 ISSR primers in a selection of cultivated bromeliads, the dissimilarity varied from 0.08 to 0.89 . According to them, the large number of polymorphic bands, combined with the wide range of dissimilarity indicates abundant genetic diversity. In the present study, among the 20 values of shorter distance, most pairs were coincidentally formed by sequential numbers of accesses in which the numbering has been assigned according to the straight-line sequence for the collection of plants. This coincidence may be directly related to the degree of relationship between genotypes. By analyzing the genetic diversity of 64 individuals of Pfaffia glomerata estimated by molecular markers (Kamada et al., 2009), similar overall results were found.

The high genetic similarity found among some genotypes is probably associated with asexual reproduction and self-fertilization events. According to Matallana et al. (2010), many species of bromeliads are self-compatible and are self-fertilized, although this breeding system can lead to loss of genetic diversity, which can consequently reduce the adaptive potential of the species when facing adverse conditions. Self-fertilization is favored in some bromeliads by natural 
selection, in certain ecological conditions. However in some species interbreeding also occurs, and is favored by flowering synchronicity, as is the case of $P$. flammea (Rocha-Pessôa and Rocha, 2008), allowing the emergence of new gene sets, and thereby promoting maintenance of genetic variability within populations (Silveira et al., 2009).

\begin{tabular}{|c|c|c|c|c|c|c|}
\hline \multirow[t]{2}{*}{ Order } & \multicolumn{3}{|c|}{ Highest distance } & \multicolumn{3}{|c|}{ Lowest distance } \\
\hline & Individuals & Populations & $d$ & Individuals & Populations & $d$ \\
\hline 1 & $42 \times 50$ & $B \times C$ & 0.8384 & $7 \times 9$ & $A \times A$ & 0.1250 \\
\hline 2 & $32 \times 55$ & $B \times C$ & 0.8155 & $5 \times 6$ & $A \times A$ & 0.1333 \\
\hline 3 & $32 \times 53$ & $B \times C$ & 0.8152 & $46 \times 47$ & $C \times C$ & 0.1395 \\
\hline 4 & $41 \times 50$ & $B \times C$ & 0.8105 & $48 \times 49$ & $\mathrm{C} \times \mathrm{C}$ & 0.1429 \\
\hline 5 & $42 \times 51$ & $B \times C$ & 0.8095 & $47 \times 48$ & $\mathrm{C} \times \mathrm{C}$ & 0.1573 \\
\hline 6 & $32 \times 54$ & $B \times C$ & 0.7965 & $47 \times 49$ & $C \times C$ & 0.1848 \\
\hline 7 & $37 \times 41$ & $B \times B$ & 0.7941 & $48 \times 51$ & $\mathrm{C} \times \mathrm{C}$ & 0.1882 \\
\hline 8 & $3 \times 55$ & $A \times C$ & 0.7917 & $46 \times 48$ & $\mathrm{C} \times \mathrm{C}$ & 0.1889 \\
\hline 9 & $12 \times 42$ & $A \times B$ & 0.7912 & $16 \times 18$ & $A \times A$ & 0.2000 \\
\hline 10 & $38 \times 50$ & $B \times C$ & 0.7843 & $18 \times 25$ & $A \times B$ & 0.2046 \\
\hline 11 & $13 \times 42$ & $A \times B$ & 0.7822 & $33 \times 34$ & $B \times B$ & 0.2065 \\
\hline 12 & $23 \times 55$ & $B \times C$ & 0.7813 & $4 \times 5$ & $A \times A$ & 0.2154 \\
\hline 13 & $41 \times 51$ & $B \times C$ & 0.7800 & $49 \times 51$ & $C \times C$ & 0.2159 \\
\hline 14 & $5 \times 53$ & $A \times C$ & 0.7791 & $30 \times 31$ & $B \times B$ & 0.2169 \\
\hline 15 & $35 \times 53$ & $B \times C$ & 0.7778 & $45 \times 48$ & $\mathrm{C} \times \mathrm{C}$ & 0.2198 \\
\hline 16 & $35 \times 55$ & $B \times C$ & 0.7766 & $16 \times 17$ & $A \times A$ & 0.2222 \\
\hline 17 & $9 \times 55$ & $A \times C$ & 0.7757 & $17 \times 18$ & $A \times A$ & 0.2222 \\
\hline 18 & $35 \times 41$ & $B \times B$ & 0.7755 & $47 \times 51$ & $C \times C$ & 0.2235 \\
\hline 19 & $1 \times 55$ & $A \times C$ & 0.7750 & $12 \times 13$ & $A \times A$ & 0.2286 \\
\hline 20 & $3 \times 53$ & $A \times C$ & 0.7750 & $46 \times 49$ & $\mathrm{C} \times \mathrm{C}$ & 0.2340 \\
\hline
\end{tabular}

According to the Jaccard similarity coefficient values, for the analyzed loci, no genotype was equal to 1 , which characterizes genetically identical individuals. The grouping by UPGMA generated from the genetic dissimilarity between individuals enabled the delimitation of three groups (Figure 1). The graphic representation is shown in Figure 1. Using the Mojema (1977) method with $\mathrm{k}=1.25$, cuts to 86.4 and $99.4 \%$ of dissimilarity are recommended. Establishing a 0.60 cut distance, which corresponds to $86.4 \%$ of the distance from the last fusion level (0.69), three similarity groups are formed: one group of 43 genotypes, the second formed by two genotypes (39 and 44$)$ and the third group with 10 genotypes. The cophenetic correlation coefficient ( $r$ ), which is the correlation between measures of original dissimilarities and those graphically formed from the dendrogram, was 0.93 .

The results of the Bayesian analysis indicated the presence of two distinct genotypes $(K=2)$ (Figure 2), according to the $\Delta K$ methodology proposed by Evanno et al. (2005). In the first group, all the genotypes of the population A, 16 genotypes of population B, and seven from population $C$ are inserted. In the second group, eight genotypes of population $B$ and four genotypes from $C$ are introduced. The results obtained with STRUCTURE are in accordance with the UPGMA method, differing only with genotypes 39 and 44 , allocated to separate groups by the grouping method. 


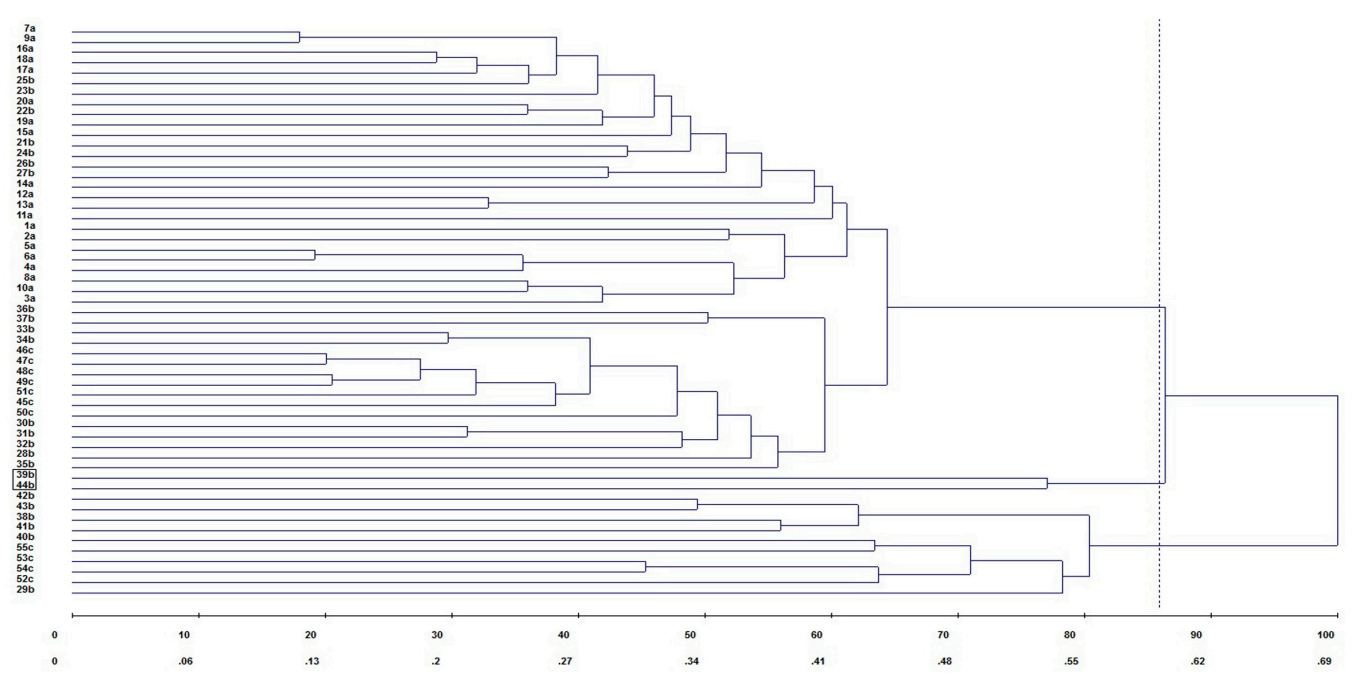

Figure 1. Dendrogram of genetic dissimilarity obtained based on ISSR markers, using the arithmetic complement of Jaccard index based on the UPGMA method for 55 genotypes of Pitcairnia flammea. The letters A, B, and C correspond to the populations in Table 1.

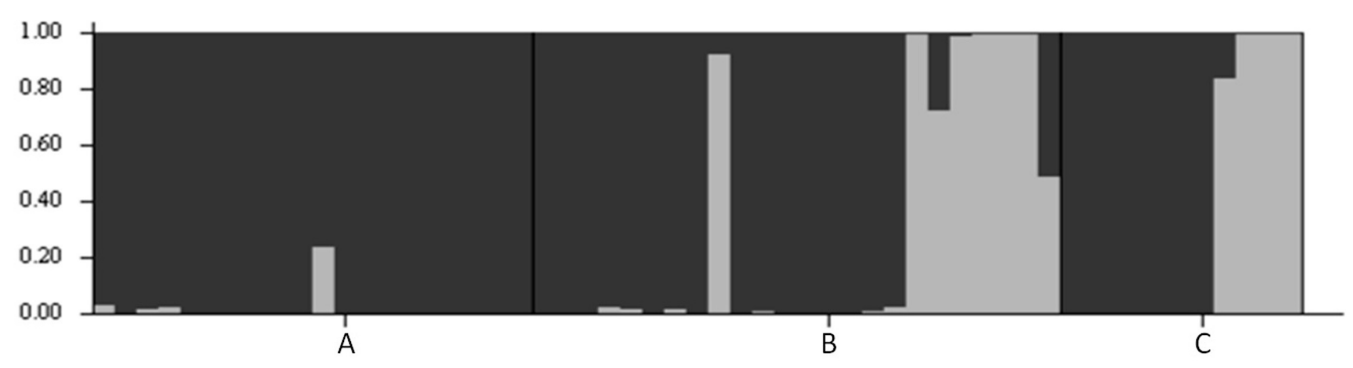

Figure 2. Structure bar plot showing the two genetic populations identified by the analysis $(K=2)$. The letters $A, B$, and C correspond to the populations in Table 1.

Through AMOVA, the genetic variation partition was carried out on two levels: within populations and among populations (Table 5). This AMOVA partition showed greater genetic variation within the population, with $90.3 \%$ of the total variation, and the remaining $9.7 \%$ of the genetic variation was observed among populations. According to Ribeiro et al. (2013), greater intra-population genetic diversity suggests the division of smaller amounts of main groups, as observed in this study. The amount of genetic differentiation of populations $\left(\Phi_{\mathrm{ST}}\right)$ was 0.0974 , indicating moderate genetic differentiation, obtained by AMOVA, and was significant $(P<0.001)$ with probabilities calculated per 1000 random permutations. The $\Phi_{\text {ST }}$ values between pairs of populations were 0.0559 between populations $B$ and $C, 0.0826$ between $A$ and $B$, and 0.1834 between $\mathrm{A}$ and $\mathrm{C}$. 
Table 5. Analysis of molecular variance based on three populations of Pitcairnia flammea.

\begin{tabular}{lrccrc}
\hline Source of variation & d.f. & Sum of squares & Variance components & Percentage of variance $(\%)$ & $P$ value \\
\hline Among populations & 2 & 1.38 & 0.026 & 9.74 & $<0.26$ \\
Within populations & 52 & 12.40 & 0.238 & 100.0 & $<0.001^{\text {** }}$ \\
Total & 54 & 13.78 & 0.264 & 1 & \\
\hline
\end{tabular}

d.f. = degrees of freedom.

According to Zanella et al. (2012), the combination of colonization history and reproduction system can influence the levels of diversity, homogenizing populations, and increasing divergence among them. The biggest $\Phi_{S T}$ found in this study was between $A$ and $C$, which, coincidentally, has greater physical distance (Table 1), indicating a higher genetic differentiation between these two populations. Overall, our data suggests moderate distinction among the three populations, since genetic differentiation between the populations indicated by $\Phi_{\mathrm{ST}}$, was only 0.0974 , and therefore, there cannot be considered to be a state of total isolation between them. Differing from the moderate value of genetic differentiation found in this study, Souza et al. (2004) studying the genetic structure in fragmented populations Chorisia speciosa, detected a high amount of genetic divergence between populations and concluded that this should be linked to the fragmentation process followed by genetic drift, meaning that the populations are isolated in the fragments. Differences in structure between plant populations are influenced by the effects of pollen and seed dispersal which are directly related to connectivity between populations, determining the flow rates of genes between them (Zanella et al., 2012).

Our results indicate that the ISSR marker was efficient in detecting polymorphism and analyzing the genetic variability of populations of $P$. flammea. Greater genetic variability found in population $\mathrm{B}$ indicate this area as an important source of genetic variability. Considering that populations are inserted in areas of territorial fragmentation under human action, the observed values of $\Phi_{S T}$ (moderate genetic differentiation) may indicate partial geographical isolation between populations.

\section{CONCLUSION}

The three populations of $P$. flammea studied have significant genetic variability indicating a good conservation status. The Bayesian approach applied to the molecular data indicated existence of two genetic groups distributed in the three locations where specimens of $P$. flammea were collected. Despite the environmental fragmentation scenario in which the samples are established, the value of $\Phi_{\text {ST }}(0.0974$, indicative of moderate genetic differentiation) indicates that gene flow rates may be enough to counteract the effects of genetic drift.

\section{Conflicts of interest}

The authors declare no conflict of interest.

\section{ACKNOWLEDGMENTS}

Fundação de Apoio à Pesquisa do Espírito Santo (FAPES) and Coordenação de Aperfeiçoamento de Pessoal de Nível Superior (CAPES), for the concession of scientific scholarship and for financial support. 


\section{REFERENCES}

Barbará T, Lexer C, Martinelli G, Mayo S, et al. (2008). Within-population spatial genetic structure in four naturally fragmented species of a neotropical inselberg radiation, Alcantarea imperialis, A. geniculata, A. glaziouana and A. regina (Bromeliaceae). Heredity 101: 285-296.

Cavallari MM, Forzza RC, Veasey EA, Zucchi MI, et al. (2006). Genetic variation in three endangered species of Encholirium (Bromeliaceae) from Cadeia do Espinhaço, Brazil, detected using RAPD markers. Biodivers. Conserv. 15: 4357-4373.

Cruz CD (2013). GENES - a software package for analysis in experimental statistics and quantitative genetics. Acta Sci. Agron. 35: 271-276.

Domingues R, Machado MA, Forzza RC, Melo TD, et al. (2011). Genetic variability of an endangered Bromeliaceae species (Pitcairnia albiflos) from the Brazilian Atlantic rainforest. Genet. Mol. Res. 10: 2482-2491.

Doyle J and Doyle J (1990). Isolation of plant DNA from fresh tissue. Focus 12: 13-15.

Earl DA and vonHoldt BM (2012). STRUCTURE HARVESTER: a website and program for visualizing STRUCTURE output and implementing the Evanno method. Conserv. Genet. Resour. 4: 359-361.

Evanno G, Regnaut S and Goudet J (2005). Detecting the number of clusters of individuals using the software STRUCTURE: a simulation study. Mol. Ecol. 14: 2611-2620.

Excoffier L, Smouse PE and Quattro JM (1992). Analysis of molecular variance inferred from metric distances among DNA haplotypes: application to human mitochondrial DNA restriction data. Genetics 131: 479-491.

Forzza R, Costa A, Filho JS, Martinelli G, et al. (2014) Bromeliaceae. Lista de Espécies da Flora do Brasil. Jardim Botânico do Rio de Janeiro, RJ.

Givnish TJ, Barfuss MHJ, Ee BV, Riina R, et al. (2011). Phylogeny, adaptive radiation, and historical biogeography in Bromeliaceae: insights from an eight-locus plastid phylogeny. Am. J. Bot. 98: 872-895.

Givnish TJ, Barfuss MH, Ee BV, Riina R, et al. (2014). Adaptive radiation, correlated and contingent evolution, and net species diversification in Bromeliaceae. Mol. Phylogenet. Evol. 71: 55-78.

Hmeljevski KV, Reis A, Montagna T and Reis MSd (2011). Genetic diversity, genetic drift and mixed mating system in small subpopulations of Dyckia ibiramensis, a rare endemic bromeliad from Southern Brazil. Conserv. Genet. 12: 761-769.

Jaccard P (1901). Etude comparative de la distribuition florale dans une porion des Alpes et des Jura. Bull. Soc. Vaudoise Sci. Nat. 37: 547-579.

Kamada T, Picoli dT, Edgard A, Alfenas AC, et al. (2009). Diversidade genética de populações naturais de Pfaffia glomerata (Spreng.) Pedersen estimada por marcadores RAPD (Spreng.) Pedersen estimada por marcadores RAPD. Acta Sci. Agron. 31: 403-409.

Martinelli G, Vieira CM, Gonzalez M, Leitman P, et al. (2008). Bromeliaceae da Mata Atlântica brasileira: lista de espécies, distribuição e conservação. Rodriguésia 59: 209-258.

Matallana G, Godinho MAS, Guilherme FAG, Belisario M, et al. (2010). Breeding systems of Bromeliaceae species: evolution of selfing in the context of sympatric occurrence. Plant Syst. Evol. 289: 57-65.

Milligan GW and Cooper MC (1985). An examination of procedures for determining the number of cluster in a data set. Psychometrika 50: 159-179.

Mojema R (1977). Hierarchical grouping methods and stopping rules: an evaluation. Comp. J. 20: 359-363.

Pamponét VC, Alves TF, Martinez RA, Corrêa RX, et al. (2013). Reduced genetic diversity in endemic Brazilian Lymania spp (Bromeliaceae) populations and implications for conservation. Genet. Mol. Res. 12: 4352-4362.

Pritchard JK, Stephens M and Donnelly P (2000). Inference of population structure using multilocus genotype data. Genetics 155: 945-959.

Ribeiro PC, Pinheiro LC, Domingues R, Forzza RC, et al. (2013). Genetic diversity of Vriesea cacuminis (Bromeliaceae): an endangered and endemic Brazilian species. Genet. Mol. Res. 12: 1934-1943.

Rocha-Pessôa TC and Rocha CFD (2008). Reproductive cycle of Pitcairnia flammea Lindl. (Bromeliaceae/Pitcairnioideae) in an insular Atlantic rainforest area in southeastern Brazil. Flora 203: 229-233.

Sgorbati S, Labra M, Grugni E, Barcaccia G, et al. (2004). A Survey of Genetic Diversity and Reproductive Biology of Puya raimondii (Bromeliaceae), the Endangered Queen of the Andes. Plant Biol. 6: 222-230.

Shannon CE and Weaver WA (1949). Mathematical model of communication. University of Illinois Press, Urbana, IL.

Silveira DG, Souza FVD, Pelacani CR, Souza AdS, et al. (2009). Micropropagation and in vitro conservation of Neoglaziovia variegata (Arr. Cam.) mez, a fiber producing bromeliad from Brazil. Braz. Arch. Biol. Technol. 52: 923-932.

Souza LMFI, Kageyama PY and Sebbenn AM (2004). Estrutura genética em populações fragmentadas de Chorisia speciosa St. Hil (Bombacaceae). Sci. Forestalis 65: 70-79.

Verma PC, Chakrabarty D, Jena SN, Mishra DK, et al. (2009). The extent of genetic diversity among Vanilla species: Comparative results for RAPD and ISSR. Ind. Crops Prod. 29: 581-589. 
Vieira SD, Rabbani ARC, Silva-Mann R, Arrigoni-Blank MdF, et al. (2013). Prospection and genetic diversity of bromeliad genera in fragmented areas. Rev. Cienci. Agrárias 56: 115-119.

Yeh FC and Boyle TJB (1997). Population genetic analysis of co-dominant and dominant markers and quantitative traits. Belg. J. Bot. 129: 157-163.

Zanella CM, Janke A, Palma-Silva C, Kaltchuk-Santos E, et al. (2012). Genetics, evolution and conservation of Bromeliaceae. Genet. Mol. Biol. 35: 1020-1026.

Zhang F, Ge Y, Wang W, Yu X, et al. (2012). Molecular characterization of cultivated bromeliad accessions with Inter-Simple Sequence Repeat (ISSR) markers. Int. J. Mol. Sci. 13: 6040-6052. 